\title{
Chest pain and left bundle branch block
}

\author{
D. LUKE GLANCY, MD, AND BAHIJ KHURI, MD
}

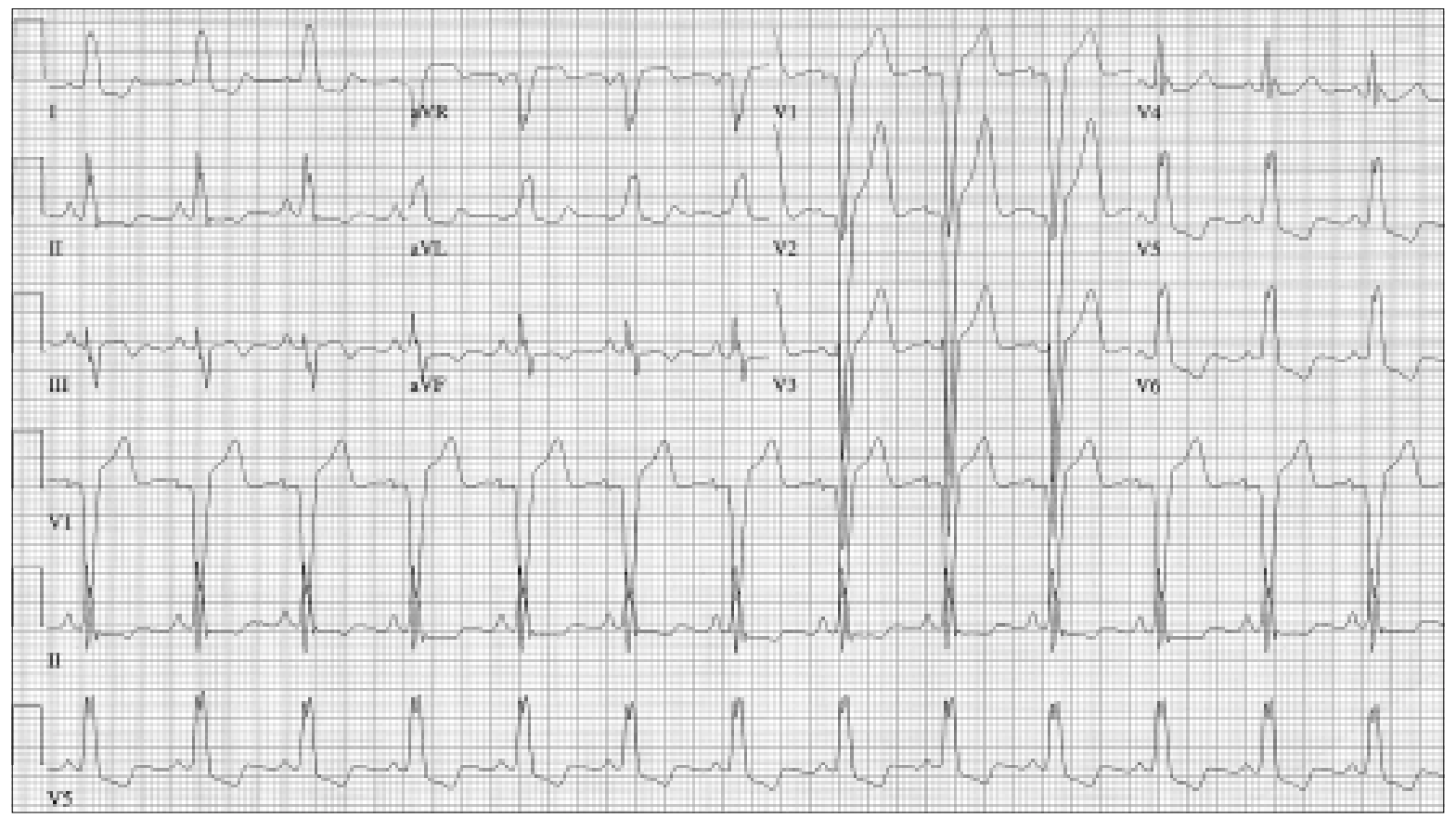

Figure 1. ECG recorded at 11:59 shows left bundle branch block and primary T-wave changes.

A 64-year-old hypertensive, diabetic woman came to the emergency department complaining of intermittent chest and left arm pain for 6 days. An electrocardiogram (ECG) showed left bundle branch block (LBBB) that was atypical because $T$ waves in the limb leads were concordant in direction with the QRS complexes instead of being discordant (Figure 1). Thus, the T-wave changes were not secondary to the conduction disturbance but were primary and suggested inferior ischemia or injury. When chest pain recurred 2 hours later, LBBB with concordant $T$ waves and QRS complexes in the limb leads persisted, and new ST-segment elevation and $Q$ waves appeared in leads III and aVF (Figure 2).

Less than an hour later the pain intensified, and the patient became diaphoretic, pale, and hypotensive. A rhythm strip showed sinus bradycardia, with a rate of 41 beats per minute. After intravenous administration of atropine, the heart rate and blood pressure increased, but the rhythm became irregular. An ECG demonstrated second-degree atrioventricular block of the Wenckebach type and striking ST-segment elevation in leads II, III, and aVF, with reciprocal changes in leads I and aVL (Figure 3).
Although atrioventricular Wenckebach occasionally occurs infra-His, which is suggested by the LBBB, in the presence of fresh inferior myocardial infarction, the block is almost certainly at atrioventricular nodal level. ST-segment elevation in lead III greatly exceeds that in lead II, suggesting right coronary occlusion with right ventricular infarction, and this is confirmed by an ECG with right-sided precordial leads (Figure 4) and by angiography (Figure 5).

Because LBBB may both obscure the ECG features of acute myocardial infarction and increase its mortality (1), current American College of Cardiology/American Heart Association guidelines recommend reperfusion therapy for all patients with LBBB whose history suggests acute myocardial infarction (2). Unfortunately, only a minority of such patients are so treated

From the Section of Cardiology, Department of Medicine, Louisiana State University Health Sciences Center and the Medical Center of Louisiana, New Orleans, Louisiana.

Corresponding author: D. Luke Glancy, MD, Section of Cardiology, Department of Medicine, Louisiana State University Health Sciences Center, 1542 Tulane Avenue, Room 441, New Orleans, Louisiana 70112. 
Figure 2. ECG recorded at 14:08 shows left bundle branch block and new ST-segment elevation and Q waves in leads III and aVF.
Figure 3. ECG recorded at 15:03 shows left bundle branch block, striking ST-T changes of acute inferior myocardial infarct, and second-degree atrioventricular block with Wenckebach periods and 2:1 block. A vertical mark has been placed over each $P$ wave in the lead II rhythm strip.
Figure 4. ECG recorded with right precordial leads at 15:13 shows left bundle branch block, first-degree atrioventricular block, further evolution of the changes of inferior myocardial infarct, and ST-segment elevation in leads $V_{2 R}$ to $V_{6 R}$ consistent with acute right ventricular infarct.
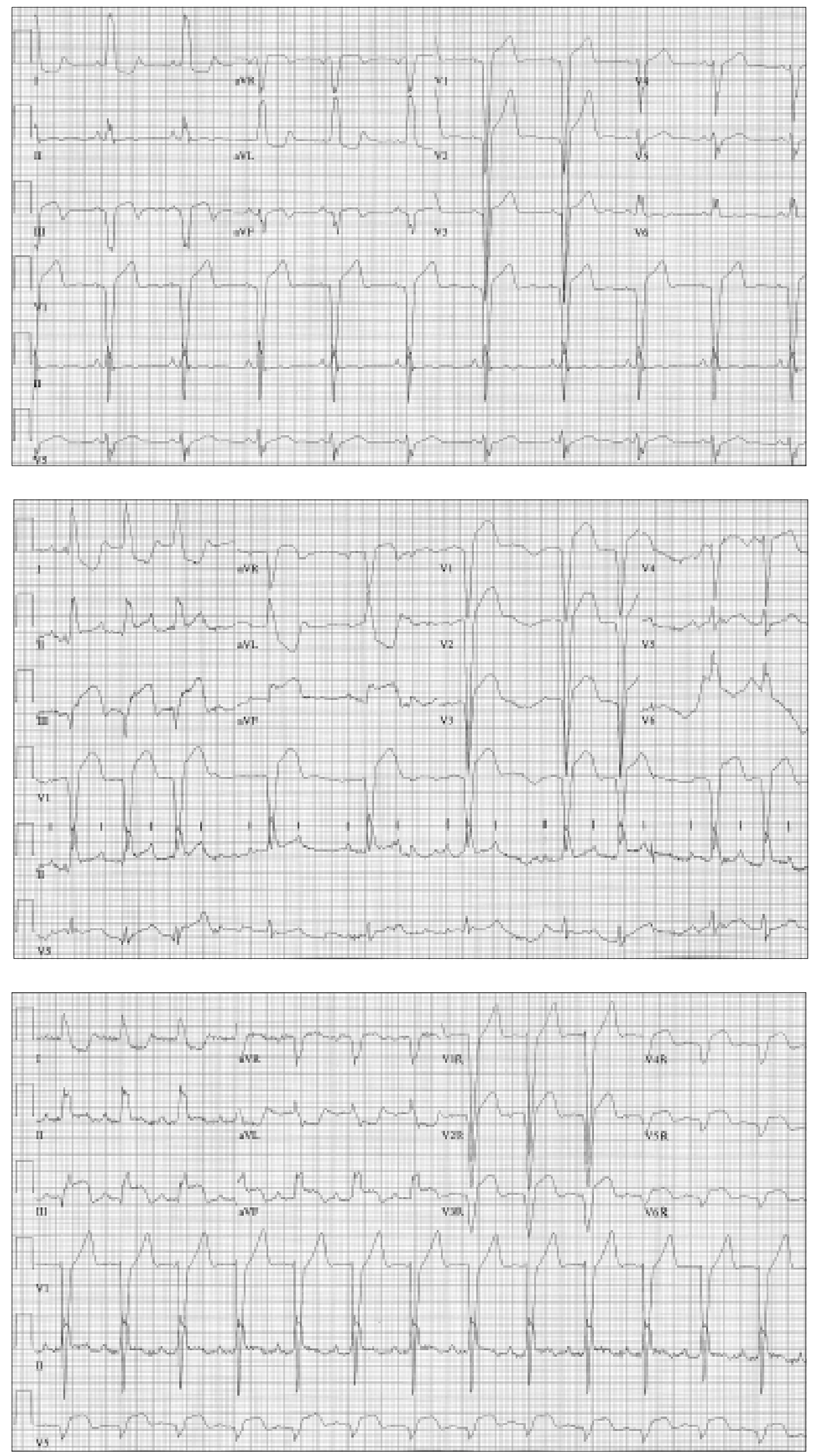


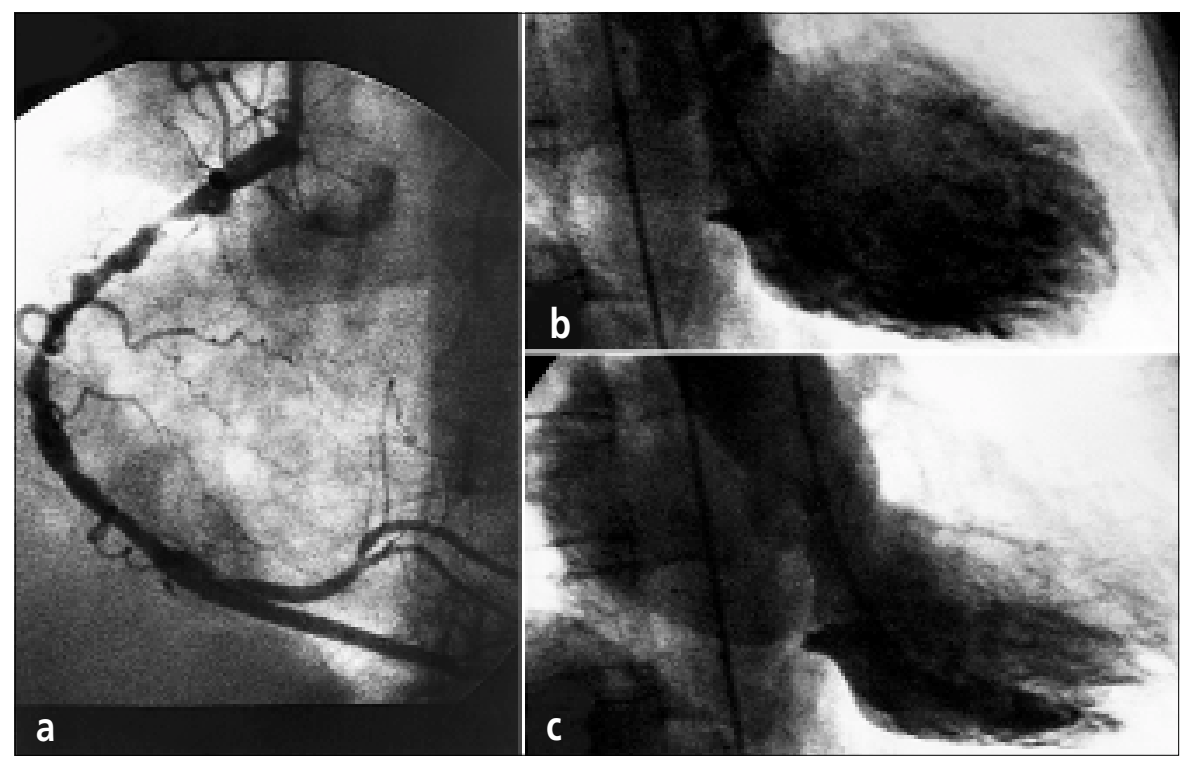

Figure 5. Angiograms performed 3 days after thrombolytic therapy. (a) Right coronary arteriogram in the left anterior oblique projection reveals a high-grade residual narrowing proximal to at least 3 right ventricular branches, the posterior descending artery, the artery to the atrioventricular node, and 2 posterolateral branches. (b) Diastolic frame of the left ventriculogram in the right anterior oblique projection. (c) Systolic frame of the left ventriculogram in the right anterior oblique projection shows akinesis of the basal three fourths of the left ventricular inferior wall and moderately severe mitral regurgitation, probably due to dysfunction of the posteromedial papillary muscle.

either in the USA or in the United Kingdom $(3,4)$. Although diagnosing acute myocardial infarction from an ECG showing LBBB may prove daunting, the GUSTO-1 trial has provided 3 ECG signs that subsequently have been validated $(5,6)$. In order of decreasing predictive value, these are ST elevation $\geq 1 \mathrm{~mm}$ in leads with a positive QRS, ST depression $\geq 1 \mathrm{~mm}$ in leads $\mathrm{V}_{1}$ to $\mathrm{V}_{3}$, and $\mathrm{ST}$ elevation $\geq 5 \mathrm{~mm}$ in leads with a negative QRS. The ECGs in Figures 3 and 4 meet the first of these criteria, and after the fourth ECG, the patient received tissue plasminogen activator. The total creatine kinase, $107 \mathrm{U} / \mathrm{L}$, was normal at the time but rose to 2599 the next morning.

Right bundle branch block usually does not obscure the ECG features of acute myocardial infarction, and at times the diagnosis of myocardial infarction can be made from the ECGs of patients with other conditions causing a wide QRS complex, such as ventricular tachycardia and right ventricular pacing $(7,8)$. Hope- fully, improved recognition of patterns of myocardial infarction in the presence of wide QRS complexes, especially LBBB, will result in more widespread and prompt use of reperfusion therapy (6).

1. Hindman MC, Wagner GS, JaRo M, Atkins JM, Scheinman MM, DeSanctis RW, Hutter AH Jr, Yeatman L, Rubenfire M, Pujura C, Rubin M, Morris JJ. The clinical significance of bundle branch block complicating acute myocardial infarction. 1. Clinical characteristics, hospital mortality, and one-year follow-up. Circulation 1978;58:679-688.

2. Ryan TJ, Antman EM, Brooks NH, Califf RM, Hillis LD, Hiratzka LF, Rapaport E, Riegel B, Russell RO, Smith EE III, Weaver WD, Gibbons RJ, Alpert JS, Eagle KA, Gardner TJ, Garson A Jr, Gregoratos G, Smith SC Jr. 1999 update: ACC/AHA Guidelines for the Management of Patients With Acute Myocardial Infarction: Executive Summary and Recommendations: A report of the American College of Cardiology/American Heart Association Task Force on Practice Guidelines (Committee on Management of Acute Myocardial Infarction). Circulation 1999;100:1016-1030.

3. Barron HV, Bowlby LJ, Breen T, Rogers WJ, Canto JG, Zhang Y, Tiefenbrunn AJ, Weaver WD. Use of reperfusion therapy for acute myocardial infarction in the United States: data from the National Registry of Myocardial Infarction 2. Circulation 1998;97:1150-1156.

4. Ketley D, Woods KL. Selection factors for the use of thrombolytic treatment in acute myocardial infarction: a population based study of current practice in the United Kingdom. The European Secondary Prevention Study Group. Br Heart J 1995;74:224-228.

5. Sgarbossa EB, Pinski SL, Barbagelata A, Underwood DA, Gates KB, Topol EJ, Califf RM, Wagner GS. Electrocardiographic diagnosis of evolving acute myocardial infarction in the presence of left bundle-branch block. GUSTO1 (Global Utilization of Streptokinase and Tissue Plasminogen Activator for Occluded Coronary Arteries) Investigators. N Engl J Med 1996;334:481-487.

6. Sgarbossa EB. Value of the ECG in suspected acute myocardial infarction with left bundle branch block. J Electrocardiol 2000;33 Suppl:87-92.

7. Castellanos A Jr, Zoble R, Procacci PM, Myerburg RJ, Berkovits BV. St-qR pattern: new sign for diagnosis of anterior myocardial infarction during right ventricular pacing. Br Heart J 1973;35:1161-1165.

8. Barold SS, Falkoff MD, Ong LS, Heinle RA. Electrocardiographic diagnosis of myocardial infarction during ventricular pacing. Cardiol Clin 1987; 5:403-417. 